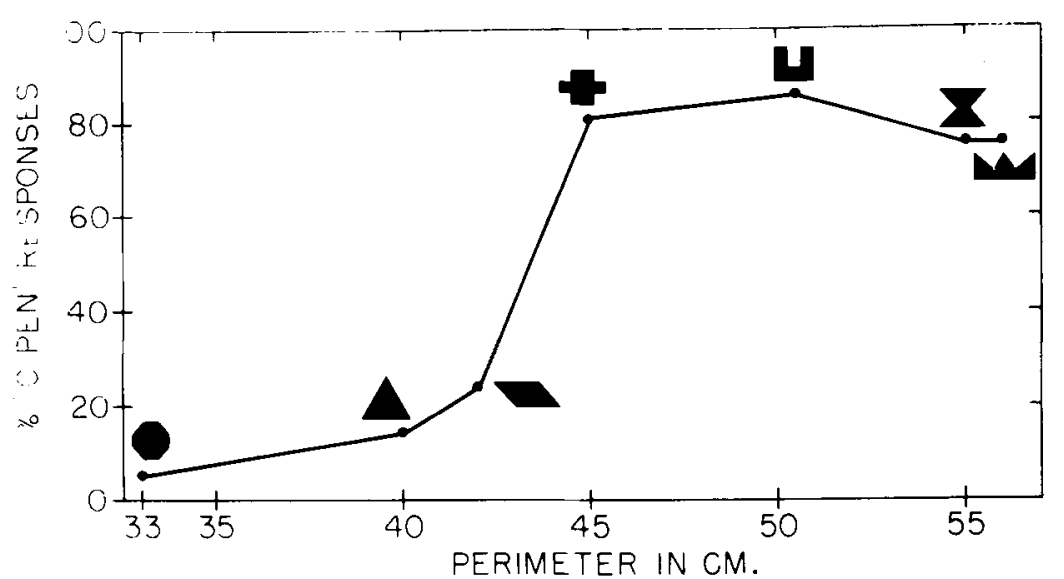

chance when tested with pairs of hexagons, triangles, and parallelograms (ps $<.001$ by $\chi^{2}$ tests), indicating that these figures were treated as similar to circles. The number of responses to the open side on trials with the remaining four figures was significantly greater than chance expectancy (ps $<.001$ by $\chi^{2}$ ), indicating that these shapes were treated as more or less equivalent to the I shape. The rank order correlations between percentage open responses to a figure and its rank in similarity to the I stimuli in perimeter and complexity were +.68 and $+.75(\mathrm{p}<.05)$, respectively. The seven figures were also ranked in terms of the sum of their ranks on both perime ter and complexity; the rank order correlation between open responses and this composite index was $+.95(\mathrm{p}<.001)$. The composite ranks represent a crude means of weighting the number of sides (complexity) by their length or conspicuity (perimeter). The fact that the correlation between the combined ranks of the stimuli and the cats' choices is so much higher than the rhos for single stimulus variables implies that the cats' behavior is controlled by both dimensions, which are only moderately correlated (rho $=+.50$ ).

\section{DISCUSSION}

Two distinct patterns of response were observed when the cats in this experiment were tested for stimulus generalization with responses to both test stimuli reinforced. Nine Ss consistently responded to position cues on the test trials, while seven others responded differentially to the visual characteristics of the test stimuli and did not display strong position biases. These disparate results are consonant with Prokasy \& Hall's (1963) argument that stimulus generalization represents a failure of discrimination. Some cats discriminated the difference between training and test figures, and quickly reverted to a more congenial pattern of responding to their preferred position on test trials with nondifferential reinforcement, while maintaining appropriate responses to the training stimuli associated with differential reinforcement. The remaining cats apparently failed to discriminate the training and test shapes and consequently responded to the position associated with reinforcement of the circle on test trials with closed figures, and to the position correlated with reinforcement of the I figure on test trials with open figures.

The interpretation of the generalization data as reflecting a failure of discrimination is supported by a previous study of form discrimination learning by cats. Derdzinski \& Warren (1969) trained groups of naive cats on simultaneous discriminations between the 10 pairings possible among circle, triangle, cross, and $U$ and I shapes. They found that cats made almost twice as many errors in learning to discriminate two open or two closed shapes than in learning to discriminate between an open and a closed form. They also obtained significant rank
DONALD C. BOUGHTON and ROBERT CLARK, Pharmaceuticals Division, E.I. du Pont de Nemours and Company, Inc., Stine Laboratory, Newark, Del. 19711

d-Amphetamine reduced the milk consumption of fasted mice in a dose-related manner. Each dose level of d-amphetamine reduced milk intake by a fixed amount,
Fig. 2. Percentage of responses to the position associated with reinforcement of the open training figure on generalization tests.

order correlations between errors to criterion and intrapair disparity in complexity $(-.79)$ and perimeter $(-.72)$. Thus, the shapes which Derdzinski and Warren found to be difficult to discriminate were treated as equivalent by the $\mathrm{Ss}$ in this experiment which generalized their responses to visual cues, and the correlations between the stimulus parameters, complexity, and perimeter, and both difficulty in discrimination learning and generalization scores are similar in magnitude.

\section{REFERENCES}

DERDZINSKI, D., \& WARREN, J. M. Perimeter, complexity and form discrimination learning by cats. Journal of Comparative \& Physiological Psychology, 1969, 68, 407-411.

HARLOW, H. F. The formation of learning sets. Psychological Review, 1949, 56, 51-65.

PROKASY, W. F., \& HALL, J.F. Primary stimulus generalization. Psychological Review, 1963, 70, 310-322.

SUTHERLAND, N. S., \& CARR, A. E. Visual discrimination of open and closed shapes by rats: II. Transfer tests. Quarterly Journal of Experimental Psychology, 1962, 14, 140-156.

WARREN, J. M., \& McGONIGLE, B. O. Attention theory and discrimination learning. In R. M. Gilbert and N. S. Sutherland (Eds.), Animal discrimination learning. London: Academic Press, 1969. Pp. 113-136. NOTES

1. This research was supported by Grant MH-04726 from the National Institute of Mental Heal th, U.S. Public Health Service.

2. Now at the University of Edinburgh, Edinburgh, Scotland.

\title{
Does d-amphetamine anorexia conform to the law of initial value?
}

which increased with dose, but which appeared to be independent of the level of milk intake of the concurrent control animals. These data suggest that the anorexic effects of d-amphetamine did not conform to the law of initial value; that is, following drug administration, the magnitude of response of the test system was not a function of, the initial state of the system. 
Table 1

Relation Between Milk Consumption of Control and D-Amphetamine Treated Mice

\begin{tabular}{lccc}
\hline Parameter & $\begin{array}{c}\text { Control (X) vs } \\
\text { Control (Y) }\end{array}$ & $\begin{array}{c}\text { Control (X) vs } \\
0.25 \mathrm{mg} / \mathrm{kg} \mathrm{d} \text {-Amph (Y) }\end{array}$ & $\begin{array}{c}\text { Control (X) vs } \\
1.0 \mathrm{mg} / \mathrm{kg} \mathrm{d} \text {-Amph (Y) }\end{array}$ \\
\hline $\mathrm{r}^{* *}$ & $0.627^{*}$ & $0.588^{*}$ & $0.450^{*}$ \\
$\mathrm{~N}$ & 90 & 48 & 67 \\
$\overline{\mathrm{X}}$ & 8.10 & 7.96 & 8.21 \\
$\sigma_{\overline{\mathrm{X}}}$ & 2.41 & 1.67 & 1.93 \\
$\overline{\mathrm{Y}}$ & 8.22 & 5.70 & 2.25 \\
$\sigma_{\bar{Y}}$ & 2.53 & 1.66 & 1.05 \\
Slope & 1.51 & 1.69 & 1.25 \\
$\mathrm{X}$ Intercept & 2.83 & 4.60 & 6.35 \\
\hline
\end{tabular}

* Significantly greater than 0.0 at the $C 01$ level or beyond by " $t$ " test.

** $r=$ product moment coefficient of correlation.

$\checkmark \bar{Y}, \bar{X}=$ mean milk consumption in drops.

d-Amphetamine decreases food intake in a dose-related manner in several species, including man (Innes \& Nickerson, 1965; Modell, 1960; Roszkowski \& Kelley, 1963; Stegen et al, 1960), and its anorexic properties have been demonstrated under many experimental conditions.

How does d-amphetamine exert its anorexic effect? Specifically, does the effect conform to the law of initial value (Wilder, 1967)? That is, does the degree of anorexia decrease when the control level of food intake is low and increase when the control level is high? The purpose of the present experiment was to relate the control level of food consumption in mice to the effect of d-amphetamine on food consumption.

\section{PROCEDURE}

The method has been described in detail elsewhere (Clark, in press). Female mice were food deprived for $23 \mathrm{~h}$ and then orally dosed with d-amphetamine $(0.25$ or $1.0 \mathrm{mg} / \mathrm{kg}$ ) or PVA-Acacia vehicle (polyvinyl alcohol $1 \%$, acacia $5 \%$, and methylparaben $0.1 \%$ in water) at $0.01 \mathrm{ml} / \mathrm{g}$ body weight. One hour after dosing, the mice were put into individual feeding

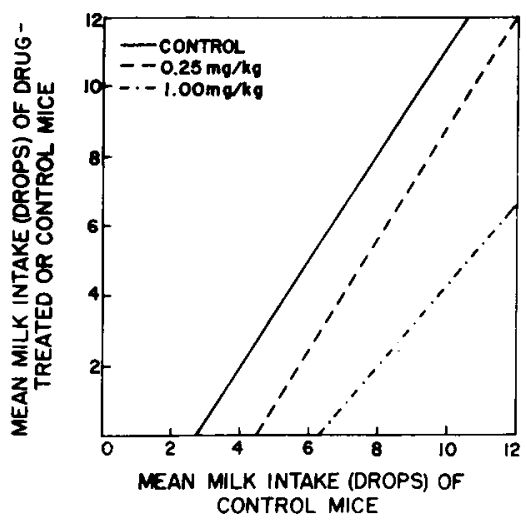

Fig. 1. Relation between mean milk intake of control and d-Amphetamine treated mice. chambers. Each chamber contained two brass bars into each of which 10 small holes had been drilled. Each hole was about half-filled with a drop $(0.05 \mathrm{ml})$ of a $50 \%$ acqueous solution of sweetened condensed milk. The mice remained in the feeding chamber for $45 \mathrm{~min}$, at which time a count was made of the number of milk drops consumed, estimated to the nearest half drop. The mice were discarded at the end of the feeding test. Typically, 40 mice were tested at a time. Data were obtained on 43 and 67 groups of 10 mice tested at $0.25 \mathrm{mg} / \mathrm{kg}$ and $1.0 \mathrm{mg} / \mathrm{kg}$ of d-amphetamine, respectively, and on 90 groups of 20 control animals.

The data were analyzed by obtaining the product-moment coefficients of correlation (r) relating the mean milk intake (in drops) of each drug-treated group to that of the concurrent control group. Also, each control group of 20 mice was randomly divided into two groups of 10 each and the mean milk intake of one group was correlated with that of the other. In addition to the correlation coefficient, the slope and intercept of each regression line was estimated by the method of least squares.

\section{RESULTS AND DISCUSSION}

The correlation coefficients ( $\mathrm{r}$ ) in Table 1 show that the milk consumption of the drug-treated animals was moderately associated with the milk consumption of the concurrently tested control animals. The $r$ value for the control vs control groups did not differ significantly from the $r$ values for the drug vs control groups. The mean milk consumption of the drug-treated animals $(\bar{Y})$ was significantly smaller than that of the concurrent control animals $(\overrightarrow{\mathrm{X}})$ at beyond the 0.01 level by $t$ test. This shows that both dose levels of d-amphetamine were effective in reducing milk consumption. It should be noted that doses of d-amphetamine greater than $1.0 \mathrm{mg} / \mathrm{kg}$ will reduce milk consumption to near zero and will thereby reduce the value of $r$ to zero. Therefore, it is not surprising that the $1.0-\mathrm{mg} / \mathrm{kg}$ dose of $\mathrm{d}$-amphetamine in the present study yielded a somewhat lower $r$ value than did the $0.25 \cdot \mathrm{mg} / \mathrm{kg}$ dose. Also, doses of d-amphetamine much lower than $0.25 \mathrm{mg} / \mathrm{kg}$ will not significantly reduce milk intake. Ineffective doses will yield values of $r$ that are the same as that of the control vs control groups. Because of the partial dependence of $r$ on dose, valid correlational data of the type presented can be obtained only over a limited portion of the d-amphetamine dose-response curve.

The slope and $X$ axis intercept values (see Table 1 and Fig. 1) give some indication of the way in which d-amphetamine reduced milk in take. The slope values did not change significantly as the dose was changed, and the intercept value increased with dose. Thus d-amphetamine reduced milk intake by a fixed amount which increased with dose, but which appeared to be independent of the control level of milk intake. The anorexic effects of d-amphetamine in this test system therefore did not conform to the law of initial value (Wilder, 1967); that is, following drug administration, the magnitude of response of the system was not a function of the initial state of the system.

The transformation of absolute data values into percentage values implies that the data follow the law of initial value. The results of the present experiment suggest therefore that the relation between the dose of d-amphetamine and milk consumption (and perhaps other measures of food intake as well) should not be expressed as a percentage of control, but rather as the absolute change from control.

\section{REFERENCES}

CLARK, R. A rapid method for testing anti-appetite drugs in mice. Toxicology \& Applied Pharmacology, in press.

INNES, I. R., \& NICKERSON, M. Drugs acting on postganglionic adrenergic nerve endings and structures innervated by them (sympathomimetic drugs). In L. S. Goodman and A. Gilman (Eds.), The pharmacological basis of therapeutics. New York: Macmillan, 1965. Pp. 477-520.

MODELL, W. Status and prospect of drugs for overeating. Journal of the American Medical Association, 1960, 173, 1131-1136.

ROSZKOWSKI, A. P., \& KELLEY, N. M. A rapid method for assessing drug inhibition of feeding behavior. Journal of Pharmacology \& Experimental Therapeutics, 1963, 140, 367-374.

STEGEN, T., ZSOSTER, H., \& CHAPPEL, C. Pharmacologic and toxicologic studies of a new anorexigenic agent: Phendimetrazine. Toxicology \& Applied Pharmacology, 1960, 2, 589-601.

WILDER, J. Stimulus and response: The law of initial value. Bristol: Wright, 1967.

$$
\text { NOTE }
$$

1. We thank Mr. E. S. Dehorty for excellent technical assistance. 